\title{
Clustering of disability caused by unintentional injury among 15- to 60-year-old: a challenge in rapidly developing countries
}

\author{
Yi-Lan Liao ${ }^{1}$, Jin-Feng Wang ${ }^{1}$, Gong Chen², Wei Du², Xin-Ming Song ${ }^{2}$, Xiao Yun ${ }^{3}$, Xiao-Ying \\ Zheng $^{2}$ \\ ${ }^{1}$ The State Key Laboratory of Resources and Environmental Information System, Institute of Geographical \\ Sciences and Nature Resources Research, Chinese Academy of Sciences, Beijing, People's Republic of China; \\ ${ }^{2}$ Institute of Population Research, Peking University, Beijing, People's Republic of China; ${ }^{3}$ National Research \\ Center for Rehabilitation Technical Aids, Ministry of Civil Affairs of the People's Republic of China, Beijing \\ 100176, People's Republic of China
}

\begin{abstract}
Little is known about disability caused by unintentional injury (accidents) worldwide. This study estimates the prevalence of disability caused by unintentional injury amongst people aged 15-60 years across different cities in the People's Republic of China with the aim of providing a scientific basis for developing prevention and control programmes. The prevalence of disability caused by unintentional injury in this target group in sampled cities across the country was estimated from data from the Second Chinese National Sample Survey on Disability. Using the statistical evolution tree approach, cities automatically clustered into a tree structure according to the level of social security and industrial structure. The KruskalWallis test was applied to compare the prevalence in various types of city. The results show that the prevalence of disability due to unintentional injury in the target population group varied significantly across the 16 types of city investigated, but that it was particularly common among the unemployed and poor. With regard to occupational structure, cities with activities oriented towards transport and construction had the highest average prevalence despite access to local, relatively sound social security systems and adequate medical resources. It was also found that people struck by unintentional injury were treated in various ways depending on the availability of social assistance, medical care and job training, which differed widely between cities depending on each city's main occupational activity. High-risk cities areas were identified for that would benefit particularly by additional medical resource allocation as it would reduce their burden of unintentional injury.
\end{abstract}

Keywords: unintentional injuries, disability, city type, spatial analysis, prevention, People's Republic of China.

\section{Introduction}

More than a billion people worldwide live with some form of disability, which translates to the largest definable, disadvantaged group in society (WHO, 2005, 2011). Disability is shared unequally and $80 \%$ of disabled people live in low-income countries (WHO, 2005). In the People's Republic of China (P.R. China), about 85 million people have a disability or a condition that affects their daily life and social activity (Peng et al., 2010). A significant proportion of these disabilities are caused by injuries (WHO, 2007) and a substantial number result in life-long disability, significant psychological trauma and subsequent financial loss (Chandran et al., 2010).

\footnotetext{
Corresponding author:

Xiao-Ying Zheng

Institute of Population Research

Peking University, Beijing 100871, People's Republic of China

Tel. +86 10 6275-6331; Fax +86 10 6275-1976

E-mail:xzheng@pku.edu.cn
}

Unintentional injuries are defined as those that occur without intent of harm, i.e. accidents (Lewit and Baker, 1995). It includes all injuries encoded as V01X59 or Y85-Y86 in the International Classification of Diseases, 10 ${ }^{\text {th }}$ Revision (ICD-10). According to estimates put forward by the Global Burden of Disease Study, unintentional injuries are responsible for more than 138 million disability-adjusted life years (DALYs) in 2004 (WHO, 2008). In P.R. China, the Ministry of Health surveyed 200,000 residents in different locations around the country from 1998-2005 whereby it was found that 200 million injuries occur annually throughout the country, 60 million of which required emergency medical treatment costing an estimated RMB 65 billion (around US\$ 9 billion), 14 million needed hospital treatment and 1 million were left permanently disabled (WHO, 2008).

Global and regional estimates of injury-specific causes of disability are lacking. However, estimates from some countries suggest that up to one quarter of disabilities may result from injury and violence. In Mexico, studies show that $17.7 \%$ of disabilities result from unintentional injuries alone, while for Hungary 
and Sierra Leone, the corresponding figures are $12.7 \%$ and $14.3 \%$, respectively (WHO, 2007). Since the 1990s, many studies have been conducted to describe characteristics of injuries in various populations in P.R. China, such as in primary and middle school students (Sun et al., 2006; Lam and Yang, 2007) and in rural residents (Xiang et al., 2000, Postel et al., 2008). However, only a minority of these studies focused on the disability of young to middle-aged people caused by unintentional injuries.

The young to middle-aged part of the population constitute the workforce that drives the gross domestic product (GDP) growth in P.R. China but this part of the population also experiences a higher risk for injuries than the rest, accounting for $51 \%$ of all deaths attributable to injuries nationwide between 2002 and 2006 (Wang et al., 2008). The disability risk in this group is affected by occupation, working conditions and a multitude of additional factors. Therefore, the prevalence of disability caused by unintentional injuries within the young to middle-aged population is related to the regional or local industrial structure, an entity whose optimal conditions varies at different stages of development (Lin, 2010). While P.R. China, as a whole, has experienced development at an unprecedented rate over the past three decades, the pace of development varies across the country. There is therefore a need to determine whether these regional variations relate to differences in industrial structure and injury prevalence rates. In addition, regional disparities exist in both economic development and in the Chinese social security expenditure. It is therefore important to study whether differences of regional development affect the disability risk of this target population.

In this study, we hypothesise that disabilities caused by unintentional injuries within the population aged 15-60 years vary across cities depending on existing social security and industrial structures. Based on data from the Office of the Second Chinese National Sample Survey on Disability (2007), our aim was to (i) explore differences in the disability prevalence in people aged 15-60 years across various city types; and (ii) reveal any discrimination faced by disabled people living in different types of cities taking into account factors such as employment, social support and health care.

\section{Material and methods}

\section{Data sources and study definition}

Data from the Second Chinese National Sample Survey on Disability, conducted in 2006 and approved by the State Council, was used. Based on stratified, multi-phased and cluster probability statistical methods, the survey sampled a total of 734 counties and 2,980 towns in the 31 provinces (including autonomous regions and municipalities) in the country. In the same way, 317 of the most important cities were further sampled form the 734 counties selected. In this survey, 2,526,145 people in 771,797 households were interviewed and the sampling ratio was 1.93 per 1,000 . The number of people aged between 15 and 60 years, which includes the great majority of the physical workforce in the country, amounted to $1,763,119$ or $69.8 \%$ of the total sample. Investigators visited each household interviewing all subjects $\geq 7$ years or age with a questionnaire developed for screening for disabled people. Experienced doctors then examined and assessed each person reported to be disabled to verify their disability. After field registrations and re-examinations were concluded, postsurvey checks were conducted to control the quality of the data. The results of the survey indicated that 161,479 people living in 142,112 households were disabled at the time of the survey (Office of the Second Chinese National Sample Survey on Disability, 2007).

Out of this number, 69,841 or as much as $43.3 \%$ of the total number of disabilities were found in the 15 60 years old group. Furthermore, 13,640 or $19.5 \%$ of these people were disabled because of unintentional injuries. Physical disability was found to be the most common type of with most people suffering from moderate grades of disability caused by trauma, mainly due to traffic accidents and working accidents.

\section{Study definitions}

During the disability examinations and assessments, the disabled subjects were asked to state the primary cause of their disability as described by Zheng et al. (2011). Many included a variety of unintentional injuries that were classified in this study as follows: disability caused by unintentional injuries such as visual disability caused by injury, trauma or toxic influence; hearing disability caused by drug intoxication, wound, accident or noise; speech disability caused by brain trauma or CO-poisoning; physical disability caused by work injury, traffic accident, spinal cord injury, brain trauma, toxic influence or other kind of trauma; intellectual disability caused by occupational injury, toxic or allergic reactions or trauma (Dai et al., 2010).

The observations, collected for the city cluster analysis, were divided into social security and factors relat- 
ed to ambient, occupational activities. The former category included information on pension insurance rates, health and medical insurance rates, unemployment insurance rates and the number of doctors per 1,000 people in 2006. The factors related to occupation included proportions of individuals employed in the following nine categories of manufacturing:

(i) production and supply of electric power, gas and water;

(ii) mining and quarrying;

(iii) geological prospecting;

(iv) construction;

(v) transport;

(vi) storage, post and telecommunications;

(vii) wholesale commerce, retail trade and catering services;

(viii)banking and insurance; and

(ix) government activities, party politics and social organization.

The tourism index was also used for data on employment in the cities since information on occupation in many cities was sparse, particularly if they had little industry. Work in the tourism business is a function of government-authorised tourism ranking and the city's non-farming population as described by Wang et al. (2012). All these data were gathered from the Local Statistical Yearbook for 2006 for each city.

\section{Data analysis}

The unbiased estimator $\hat{\bar{Y}}_{u}$ and unbiased variance estimator $v\left(\hat{\bar{Y}}_{u}\right)$ of initial prevalence rates of disabilities caused by unintentional injury in the target population aged from 15-60 years across each sample city were first computed by multi-phase cluster sampling equations as follows:

$$
\begin{gathered}
\hat{\bar{Y}}_{u}=\frac{N}{n \times M_{0}} \sum_{i=1}^{n} M_{i} \bar{y}_{i} \\
v\left(\hat{\bar{Y}}_{u}\right)=\frac{1}{M_{0}^{2}} \times\left[\frac{N^{2} \times\left(1-\frac{n}{N}\right)}{n} \times \frac{\sum_{i=1}^{n}\left(\hat{Y}_{i}-\frac{1}{n} \times \sum_{i=1}^{n} \hat{Y}_{i}\right)^{2}}{n}\right]+ \\
\frac{N}{n} \times \sum_{i=1}^{n} \frac{M_{i}^{2} \times\left(1-\frac{m_{i}}{M_{i}}\right) \times \frac{1}{m_{i}-1} \times \sum_{j=1}^{m_{i}}\left(y_{i j} \bar{y}_{i}\right)^{2}}{m_{i}}
\end{gathered}
$$

where $N$ and $n$ are the numbers of all counties and sample counties belonging to a city, respectively. $M_{i}$ and $m_{i}$ are the number of all towns and sample towns belonging to the county $i . M_{o}$ is the total number of counties. The term $y_{i j}$ indicates the rate of people with disabilities in county $i$ and town $j$, while $\bar{y}_{i}$ represents the average rate of county $i$ and $\hat{Y}_{i}$ is the sum of the estimated rate of county $i$. The conservative confidence intervals for $\hat{\bar{Y}}_{u}$ were calculated as $\hat{\bar{Y}}_{u} \pm t\left(v\left(\hat{\bar{Y}}_{u}\right)\right)$ where $t()$ is the upper $\alpha / 2$ critical value from the $t(\mathrm{n}-1)$ distribution.

To provide a single summary measure, the initial prevalence rates of disabilities caused by unintentional injury in each sample city was then adjusted for population structure.

\section{The city tree approach}

The 317 sample cities were categorised with regard to their preferred industrial activity and their standing with regard to social security, each category consisting of one of five choices and both labelled from 1 to 5 as indicated below.

Industrial activity:

(i) industry and commerce;

(ii) medium-sized, diversified cities;

(iii) mining cities;

(iv) small, lacking heavy industry; and

(v) transport and construction.

Social security:

(i) relatively good social insurance rates;

(ii) backward areas with low social security;

(iii) good medical care but low insurance participation;

(iv) sound social security, adequate medical resources; and

(v) good social security but poor medical infrastructure.

Tables 1 and 2 present the occupational and social security groups classified through the national sample survey with the arithmetic mean value and standard deviation (SD) given for each classification variable.

Among all possible combinations of industrial activity and social security $\left(5^{5}\right.$ or 3,125$)$, most combinations do not exist in the real world. However, it was still needed to find an arbiter to group cities into a useful number of categories. To achieve this, a partitioning approach based on Ward's cluster method (Ward, 1963) and the evolution tree approach (Wang et al., 2012) was applied, in which the sample cities were categorised into just different 16 types as follows:

(I) medium-sized, industrially diversified cities with fairly high social insurance rates; 
(II) industry-oriented, commercial cities with relatively high social insurance rates;

(III) mining cities with relatively high social insurance rates;

(IV) small cities with relatively high social insurance rates but no leading industries;

(v) cities based on heavy industry and transport (export/import) with relatively high social insurance rates;

(VI) medium-sized, industrially diversified cities with inadequate social security system;

(VII) industry-oriented, commercial cities with inadequate social security system;

(VIII) mining cities with inadequate social security system;

(IX) small cities with inadequate social security system and no leading industries;

(x) cities based on heavy industry and transport (export/import) with inadequate social security system;

(XI) medium-sized, industrially diversified cities with good medical infrastructure but low insurance participation;

(XII) mining cities with good medical infrastructure but low insurance participation;

(XIII) small cities with good medical infrastructure but low insurance participation and no leading industries;

(XIV) medium-sized, industrially diversified cities with relatively sound social security systems and adequate human medical resources;

(XV) cities based on heavy industry and transport (export/import) with relatively sound social security systems and adequate human medical resources; and

(XVI) medium-sized, industrially diversified cities with good social security systems but poor medical infrastructure.

The various ways of partitioning and combining the sample cities can be schematically shown as a tree with 16 branches, each corresponding to a type of city, where the leaves symbolise the cities themselves (Fig. 1 ). In the figure, each leaf is labelled with a code, the first digit of which specifies the city's industrial preference and the second the level of social security, while the colour of the leaf signifies the level of disability, where red indicates high prevalence and yellow the opposite.

Table 1. Mean and standard deviation (SD) of common occupational factors.

\begin{tabular}{|c|c|c|c|c|c|c|c|c|c|c|c|c|}
\hline \multirow[b]{2}{*}{ City type } & \multirow[b]{2}{*}{ No. } & \multirow[b]{2}{*}{$\begin{array}{c}\text { Statistic } \\
\text { metric }\end{array}$} & \multicolumn{10}{|c|}{ Sector } \\
\hline & & & 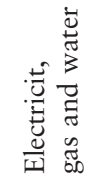 & 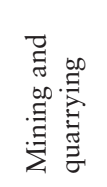 & 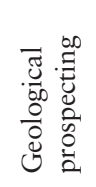 & 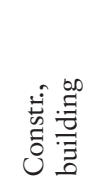 & 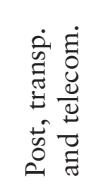 & 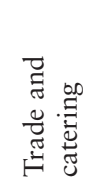 & 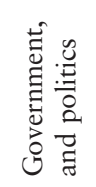 & 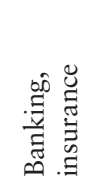 & 离: & 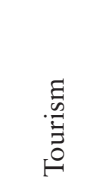 \\
\hline $\begin{array}{l}\text { Industry and } \\
\text { commerce } \\
\text { (1) }\end{array}$ & 52 & $\begin{array}{l}\text { Mean } \\
\text { SD }\end{array}$ & $\begin{array}{l}0.280^{\mathrm{b}} \\
0.140\end{array}$ & $\begin{array}{l}0.009 \\
0.010\end{array}$ & $\begin{array}{l}0.002 \\
0.001\end{array}$ & $\begin{array}{l}0.053^{\mathrm{b}} \\
0.015\end{array}$ & $\begin{array}{l}0.042^{c} \\
0.012\end{array}$ & $\begin{array}{l}0.123^{\mathrm{b}} \\
0.034\end{array}$ & $\begin{array}{l}0.030 \\
0.012\end{array}$ & $\begin{array}{l}0.010^{c} \\
0.004\end{array}$ & $\begin{array}{l}0.106^{c} \\
0.044\end{array}$ & $\begin{array}{l}22.970 \\
64.996\end{array}$ \\
\hline $\begin{array}{l}\text { Medium-sized, } \\
\text { diversified cities } \\
\text { (2) }\end{array}$ & 87 & $\begin{array}{l}\text { Mean } \\
\text { SD }\end{array}$ & $\begin{array}{l}0.115 \\
0.063\end{array}$ & $\begin{array}{l}0.009 \\
0.009\end{array}$ & $\begin{array}{l}0.001 \\
0.001\end{array}$ & $\begin{array}{l}0.029 \\
0.010\end{array}$ & $\begin{array}{l}0.026 \\
0.006\end{array}$ & $\begin{array}{l}0.064 \\
0.018\end{array}$ & $\begin{array}{l}0.024 \\
0.005\end{array}$ & $\begin{array}{l}0.006 \\
0.001\end{array}$ & $\begin{array}{l}0.056 \\
0.009\end{array}$ & $\begin{array}{c}5.517 \\
12.651\end{array}$ \\
\hline $\begin{array}{l}\text { Mining cities } \\
\text { (3) }\end{array}$ & 52 & $\begin{array}{l}\text { Mean } \\
\text { SD }\end{array}$ & $\begin{array}{l}0.102 \\
0.036\end{array}$ & $\begin{array}{l}0.030^{\mathrm{d}} \\
0.027\end{array}$ & $\begin{array}{l}0.003^{c} \\
0.003\end{array}$ & $\begin{array}{l}0.026 \\
0.009\end{array}$ & $\begin{array}{l}0.039^{\mathrm{d}} \\
0.011\end{array}$ & $\begin{array}{l}0.078 \\
0.018\end{array}$ & $\begin{array}{c}0.035^{\mathrm{d}} \\
0.011\end{array}$ & $\begin{array}{l}0.008^{\mathrm{d}} \\
0.002\end{array}$ & $\begin{array}{l}0.080 \\
0.015\end{array}$ & $\begin{array}{l}4.163 \\
7.481\end{array}$ \\
\hline $\begin{array}{l}\text { Small, lacking } \\
\text { heavy industry } \\
\text { (4) }\end{array}$ & 116 & $\begin{array}{l}\text { Mean } \\
\text { SD }\end{array}$ & $\begin{array}{l}0.043 \\
0.020\end{array}$ & $\begin{array}{l}0.008 \\
0.011\end{array}$ & $\begin{array}{l}0.001 \\
0.001\end{array}$ & $\begin{array}{l}0.011 \\
0.005\end{array}$ & $\begin{array}{l}0.015 \\
0.005\end{array}$ & $\begin{array}{l}0.036 \\
0.011\end{array}$ & $\begin{array}{l}0.022 \\
0.015\end{array}$ & $\begin{array}{l}0.004 \\
0.001\end{array}$ & $\begin{array}{l}0.040 \\
0.010\end{array}$ & $\begin{array}{c}7.869 \\
16.252\end{array}$ \\
\hline $\begin{array}{l}\text { Transport and } \\
\text { construction } \\
\text { (5) }\end{array}$ & 10 & $\begin{array}{l}\text { Mean } \\
\text { SD }\end{array}$ & $\begin{array}{l}0.166 \\
0.062\end{array}$ & $\begin{array}{l}0.103^{\mathrm{b}} \\
0.044\end{array}$ & $\begin{array}{l}0.003^{c} \\
0.002\end{array}$ & $\begin{array}{l}0.045^{\mathrm{c}} \\
0.020\end{array}$ & $\begin{array}{l}0.076^{\mathrm{b}} \\
0.026\end{array}$ & $\begin{array}{l}0.106^{c} \\
0.016\end{array}$ & $\begin{array}{c}0.049^{b} \\
0.011\end{array}$ & $\begin{array}{l}0.013^{\mathrm{d}} \\
0.003\end{array}$ & $\begin{array}{l}0.119^{b} \\
0.027\end{array}$ & $\begin{array}{l}1.059 \\
3.273\end{array}$ \\
\hline Total & 317 & $\begin{array}{l}\text { Mean } \\
\text { SD }\end{array}$ & $\begin{array}{l}0.116 \\
0.105\end{array}$ & $\begin{array}{l}0.016 \\
0.027\end{array}$ & $\begin{array}{l}0.002 \\
0.002\end{array}$ & $\begin{array}{l}0.027 \\
0.018\end{array}$ & $\begin{array}{l}0.029 \\
0.018\end{array}$ & $\begin{array}{l}0.068 \\
0.036\end{array}$ & $\begin{array}{l}0.027 \\
0.013\end{array}$ & $\begin{array}{l}0.006 \\
0.004\end{array}$ & $\begin{array}{l}0.065 \\
0.034\end{array}$ & $\begin{array}{c}8.771 \\
29.355\end{array}$ \\
\hline
\end{tabular}

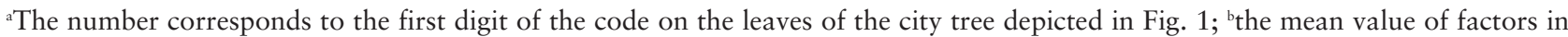
the city type $\geq$ population mean of factors in all cities $+1.5 \times$ the population SD of factors in all cities; 'the mean value of factors in the city type $\geq$ population mean of factors in all cities + the population SD of factors in all cities; ${ }^{\mathrm{d}}$ the mean value of factors in the city type $\geq$ population mean of factors in all cities $+0.5 \times$ the population SD of factors in all cities. 
Table 2. Mean and standard deviation (SD) of social security factors.

\begin{tabular}{|c|c|c|c|c|c|c|}
\hline \multirow[b]{2}{*}{ City type ${ }^{a}$} & \multirow[b]{2}{*}{ No. } & \multirow[b]{2}{*}{$\begin{array}{l}\text { Statistic } \\
\text { metric }\end{array}$} & \multicolumn{4}{|c|}{ Sector } \\
\hline & & & $\begin{array}{l}\text { Pension } \\
\text { insurance } \\
\text { rates }\end{array}$ & $\begin{array}{l}\text { Health and } \\
\text { medical } \\
\text { insurance rates }\end{array}$ & $\begin{array}{l}\text { Unemployment } \\
\text { insurance } \\
\text { rates }\end{array}$ & $\begin{array}{l}\text { Number of } \\
\text { doctors per } \\
1,000 \text { people }\end{array}$ \\
\hline $\begin{array}{l}\text { Cities with good social } \\
\text { insurance rates } \\
\text { (1) }\end{array}$ & 59 & $\begin{array}{l}\text { Mean } \\
\text { SD }\end{array}$ & $\begin{array}{l}0.204^{c} \\
0.107\end{array}$ & $\begin{array}{l}0.239^{c} \\
0.096\end{array}$ & $\begin{array}{l}0.164^{c} \\
0.071\end{array}$ & $\begin{array}{l}0.002 \\
0.001\end{array}$ \\
\hline $\begin{array}{l}\text { Backward areas with low } \\
\text { social security } \\
\text { (2) }\end{array}$ & 225 & $\begin{array}{l}\text { Mean } \\
\text { SD }\end{array}$ & $\begin{array}{l}0.063 \\
0.036\end{array}$ & $\begin{array}{l}0.071 \\
0.034\end{array}$ & $\begin{array}{l}0.054 \\
0.026\end{array}$ & $\begin{array}{l}0.001 \\
0.000\end{array}$ \\
\hline $\begin{array}{l}\text { Good medical care but low } \\
\text { insurance participation } \\
\text { (3) }\end{array}$ & 26 & $\begin{array}{c}\text { Mean } \\
\text { SD }\end{array}$ & $\begin{array}{l}0.046 \\
0.033\end{array}$ & $\begin{array}{l}0.085 \\
0.034\end{array}$ & $\begin{array}{l}0.046 \\
0.021\end{array}$ & $\begin{array}{l}0.004^{b} \\
0.001\end{array}$ \\
\hline $\begin{array}{l}\text { Sound social security with } \\
\text { adequate medical resources } \\
\text { (4) }\end{array}$ & 4 & $\begin{array}{l}\text { Mean } \\
\text { SD }\end{array}$ & $\begin{array}{l}0.219^{\mathrm{c}} \\
0.136\end{array}$ & $\begin{array}{l}0.250^{c} \\
0.076\end{array}$ & $\begin{array}{l}0.140^{c} \\
0.040\end{array}$ & $\begin{array}{l}0.007^{b} \\
0.001\end{array}$ \\
\hline $\begin{array}{l}\text { Good social security but } \\
\text { poor medical infrastructure } \\
\text { (5) }\end{array}$ & 3 & $\begin{array}{l}\text { Mean } \\
\text { SD }\end{array}$ & $\begin{array}{c}0.595^{\mathrm{b}} \\
0.041\end{array}$ & $\begin{array}{c}0.619^{b} \\
0.070\end{array}$ & $\begin{array}{c}0.503^{b} \\
0.119\end{array}$ & $\begin{array}{l}0.003 \\
0.000\end{array}$ \\
\hline Total & 317 & $\begin{array}{c}\text { Mean } \\
\text { SD }\end{array}$ & $\begin{array}{l}0.099 \\
0.100\end{array}$ & $\begin{array}{l}0.116 \\
0.103\end{array}$ & $\begin{array}{l}0.082 \\
0.076\end{array}$ & $\begin{array}{l}0.002 \\
0.001\end{array}$ \\
\hline
\end{tabular}

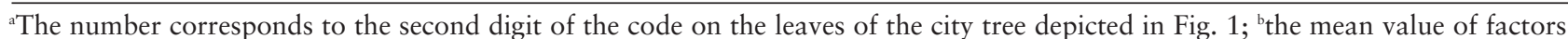
in the city type $\geq$ population mean of factors in all cities $+1.5 \times$ the population SD of factors in all cities; "the mean value of factors in the city type $\geq$ population mean of factors in all cities + the population SD of factors in all cities; ${ }^{\mathrm{d}}$ the mean value of factors in the city type $\geq$ population mean of factors in all cities $+0.5 \times$ the population SD of factors in all cities.

The number of cities in each class (i.e. branch on the city tree) was determined by Ward's method, according to which all cities were taken as collection points that initially contained only a single unit. Then the pairs of cities yielding the smallest increase in the error sum of squares were added together merging into clusters with the potential to grow along with each step in a continued series of pairings. The error sum of squares is a measure of the total sum of squared deviations of each case from the mean for a cluster (Ward, 1963). If we let $V_{t c k}$ denote the value of the variable $k$ in the city $c$ belonging to city type $t$, the error sum of squares can be defined as:

$$
E S S=\sum_{t} \sum_{k} \sum_{c}\left|V_{t c k}-\bar{V}_{t \cdot k}\right|
$$

where $\bar{V}_{t \cdot k}$ is the mean value of the variable $k$ in the cities belonged to city type $t$. The method was carried on until all cities had been combined into clusters. In contrast to the k-means algorithm, Ward's method provides guidance about what the cluster number should be. According to this method, the increase in the error sum of squares when combining two clusters is taken as the cost of merging into a cluster combination, where the ideal cluster number is that immedi- ately before the subtraction of the merging cost. During every classification step, the city groups were identified as described by Nelson (1955), in which, the mean of the various factors is considered as the "standard of functional structure" and the SD was used to measure functional importance.

The Kruskal-Wallis test (1952) was used to compare the averages involved in the prevalence of disability caused by unintentional injury among the target population across the 16 types of city. All analyses were conducted by SPSS Win 16.0 with a $95 \%$ level of significance. Based on Ward's cluster method (1963) and the nine categories of manufacturing and social security factors, the sample cities were sorted into two of the five groups below, the numbers of which correspond to those on the leaves described above and shown in Fig. 1.

\section{Results}

The prevalence rate of disabilities caused by unintentional injury amongst the target population aged $15-60$ years $\left(\mathrm{x}^{2}=38.93, \mathrm{P}=0.001\right)$ differed significantly among the city types. As shown in Fig. 1, we found high disability prevalence rates concentrated in 


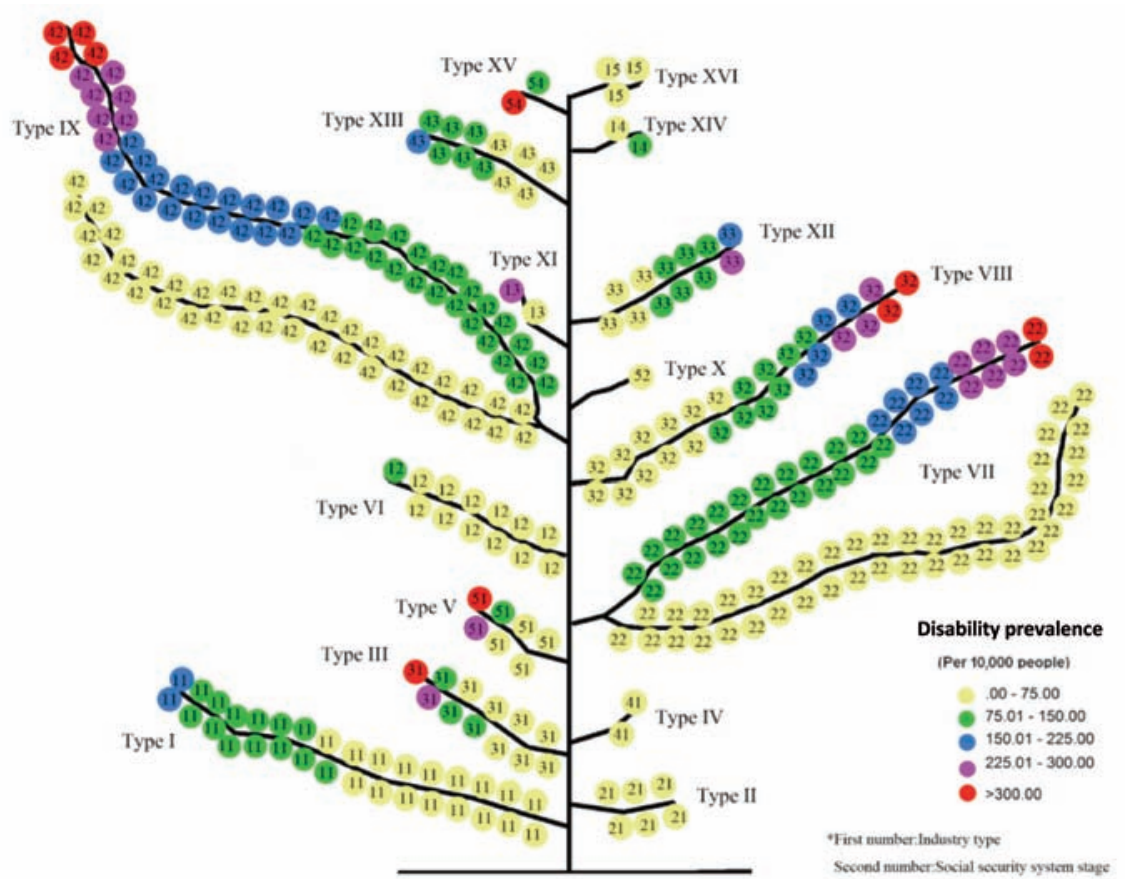

(a) City tree

Fig. 1. The city tree of disability.

city types VII, VIII and IX, city types representing backward areas with regard to social security. Cities of types VII and VIII had no leading industries, while type IX are the mining cities. Not surprisingly, the latter had high risk for unintentional injuries. The two individual cities with high prevalence rate were Tieling in Liaoning province and Rikaze in Tibet belonging to type VII and IX, respectively. However, the highest average prevalence rate appeared in city type $\mathrm{XV}$, which are the cities that have heavy industry and much transport activities but also relatively sound social security systems and adequate human medical resources (Fig. 2). In contrast, the average prevalence rate in city type IV (small cities with relatively high social insurance rates but no leading industries) was the lowest. These cities were the industry-oriented commercial cities with relatively sound social security systems and adequate human medical resources.

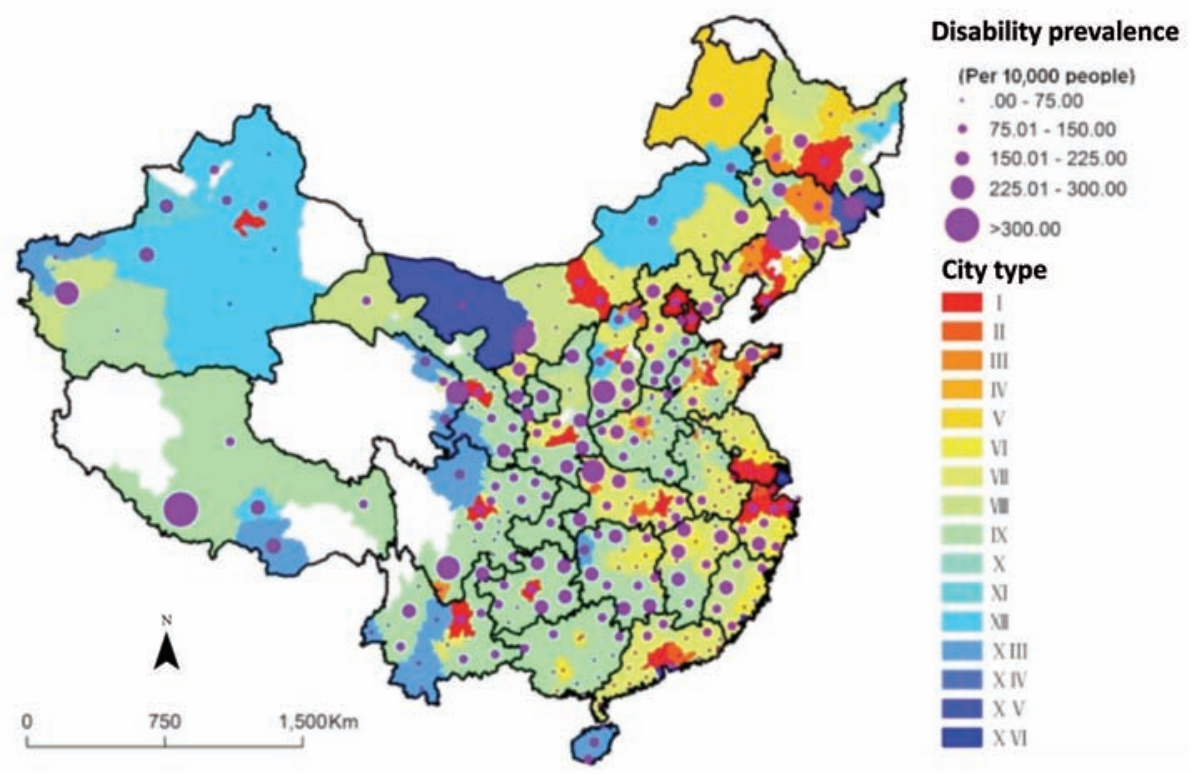

Fig. 2. The country-wide spatial distribution of disability at the city level (colour of provincial areas with prominent cities indicate the general city type in that area). 


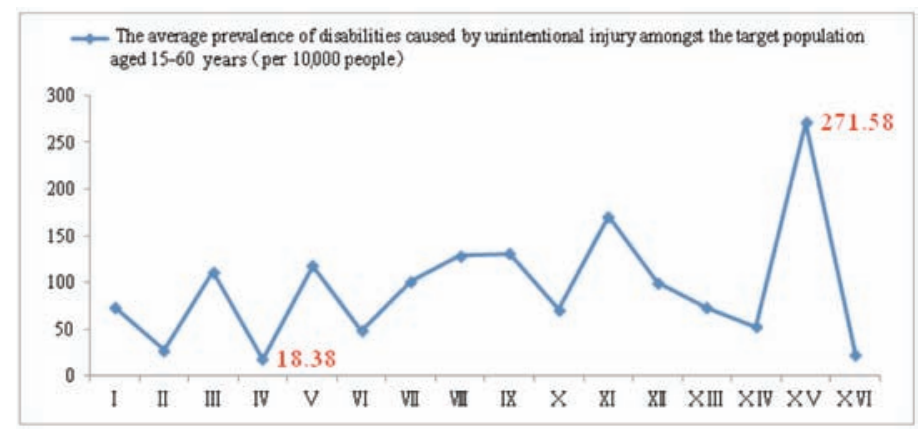

Fig. 3. The average prevalence of disabilities caused by unintentional injury amongst the target population aged 15-60 years across various city types.

Fig. 3 indicates that physical disability was the most common type of disability within the surveyed target population. The proportion of subjects with multiple disabilities was small. Of the target population, about $90 \%$ were moderately to mildly disabled and suffered from grade- 3 or grade- 4 disabilities according to the documentation of the Second China National Sample Survey on Disability that details the grading standard for each disability (Office of the Second China National Sample Survey on Disability, 2007). The most common causes of injury-related disabilities amongst the target population were trauma, traffic accidents and working injuries; these causes accounted for $80 \%$ of all disabilities. Preventive measures should therefore focus on these high-risk groups and be adapted to the composition of the injury-related disability.

It was found that cities specializing in transport and construction (XV) had the highest average prevalence rates in spite of relatively sound social security systems and adequate human medical resources. Higher unintentional injury-related disabilities were found to occur in border trade cities such as Alashan (near the Mongolia People's Republic) and Yanbian (near the Democratic People's Republic of Korea) and the survey data indicated that $58 \%$ of the unintentional injuries had struck people belonging to the minority cultures who had come from rural areas.

The national sample survey data showed that regardless of the industry structure, the employment rate of people with disabilities caused by unintentional injury was very low in most cities. The Liangshan Yi Autonomous Prefecture, belonging to city type IX, reported the maximum employment rate of these people of only $5.9 \%$ and with low wage rates. As seen in Fig. $4 \mathrm{c}$, less than $25 \%$ of disabled people have a per capita annual income exceeding RMB 6,000 (around US\$ 830) in most of the city types. Two major sources of discrimination were identified: (i) individual factors and (ii) organizational factors. With respect to (i), most

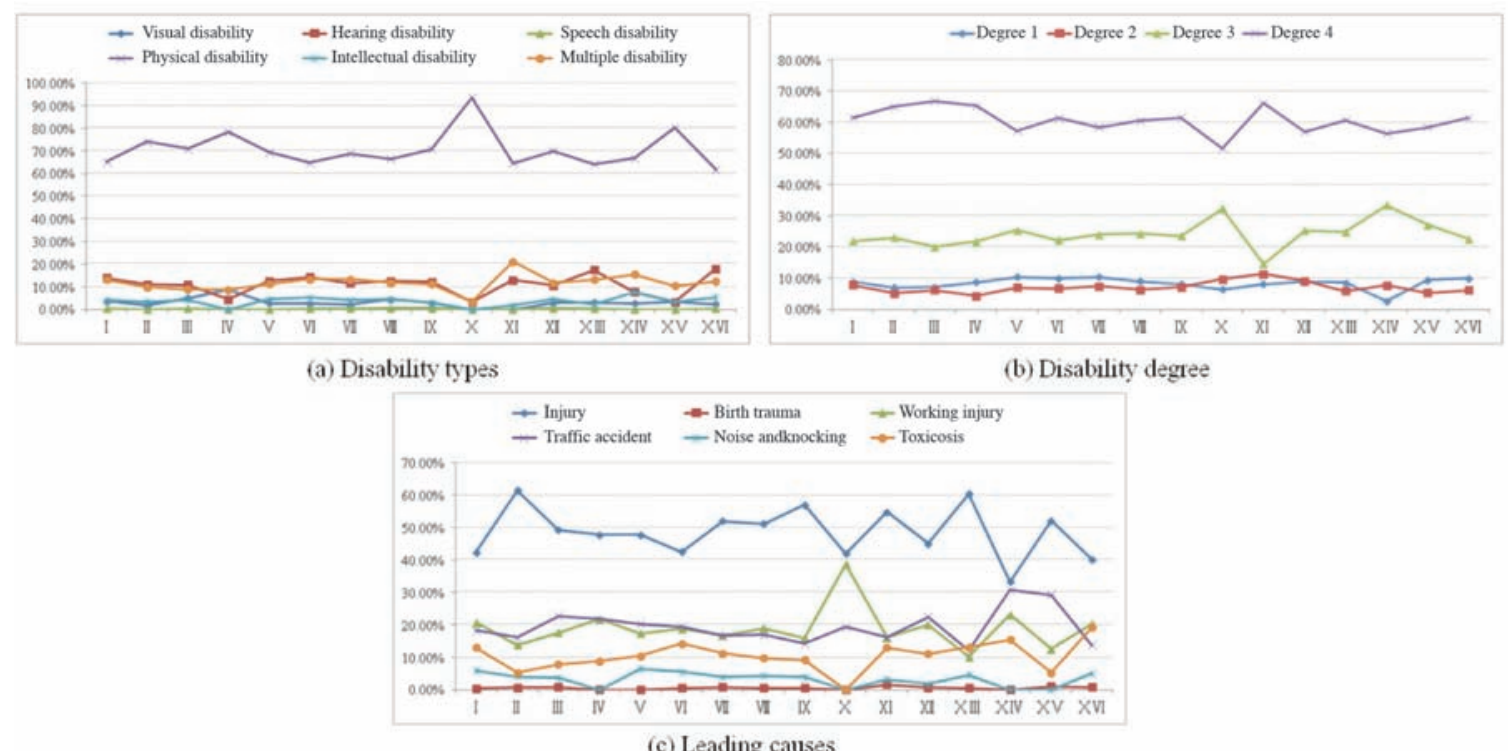

Fig. 4. The nature of disabilities caused by unintentional injury amongst the target population aged 15-60 years across various city types. 


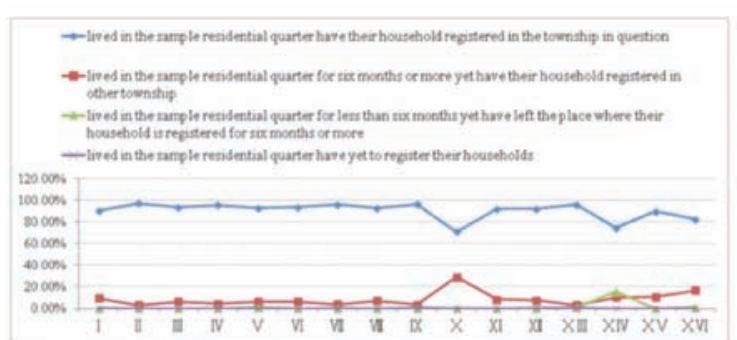

(a) Residential address

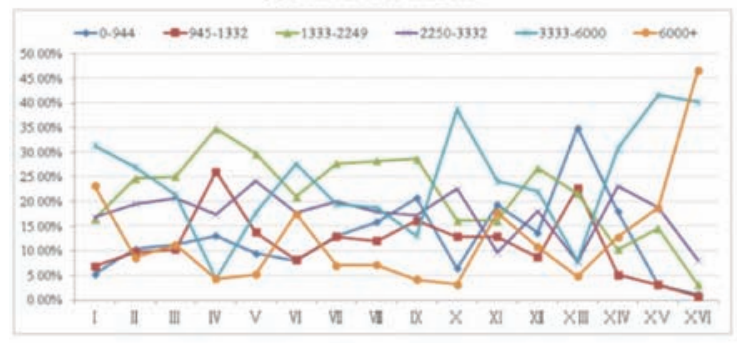

(c) Household income

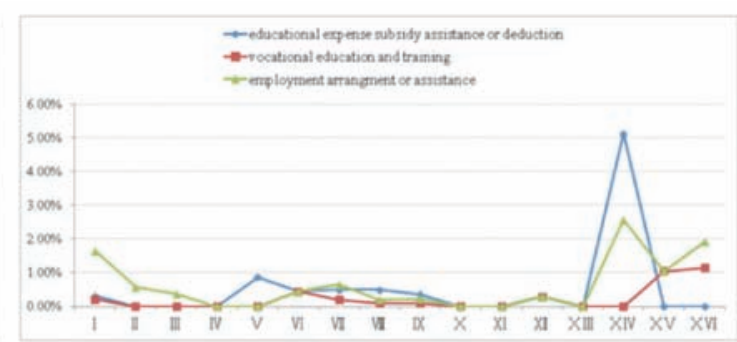

(b) Status of vocational education

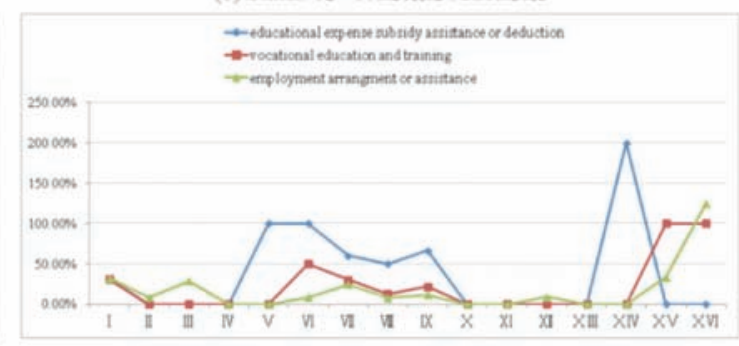

(d) Requirement satisfaction about vocational education

Fig. 5. Employment status of unintentionally injured disabled people aged 15-60 years across various city types.

disabled people suffered from moderate to mild physical disabilities but with a degree ensuring that they must find a job close to home. Fig. 4 illustrates that less than $20 \%$ of disabled people left their registered home for six months or more. (ii) Organizational factors (Gwen, 1997). In the survey, only $1 \%$ of disabled people were offered and had accepted vocational education and training and less than $3 \%$ of disabled people received an employment arrangement or assistance.

The required satisfaction index varies significantly among city types. In city types XV and XVI, disabled people's requirements for vocational education and employment assistance had largely been met, in contrast to cities belonging to type IV, $\mathrm{X}$ and $\mathrm{XI}$.

People with disabilities in most city types could not use assistive appliances that they deserved to have access to (Fig. 5d). Economics played a part, with half of the disabled people unable to afford health care as compared with a third of the population without disability (Lancet 2011). It was noted that few requirements for rehabilitation training were met. The government should play a greater role in the rehabilitation of the disabled. Disability and poverty are intricately linked (Mont and Loeb, 2010). Roughly 10-12\% of

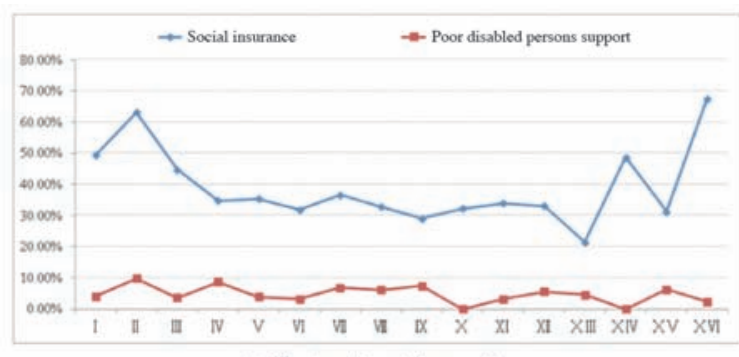

(a) Status of social security

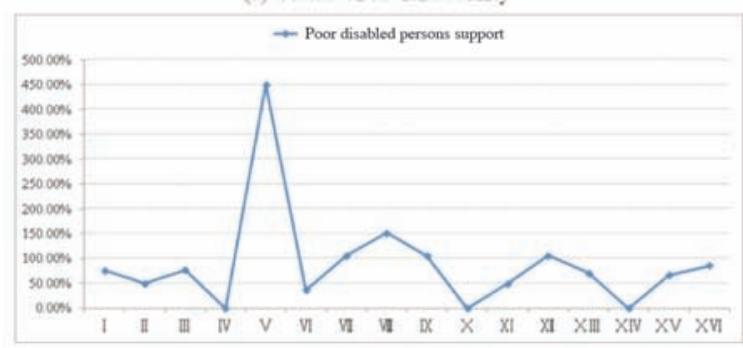

(c) Requirement satisfaction about social support

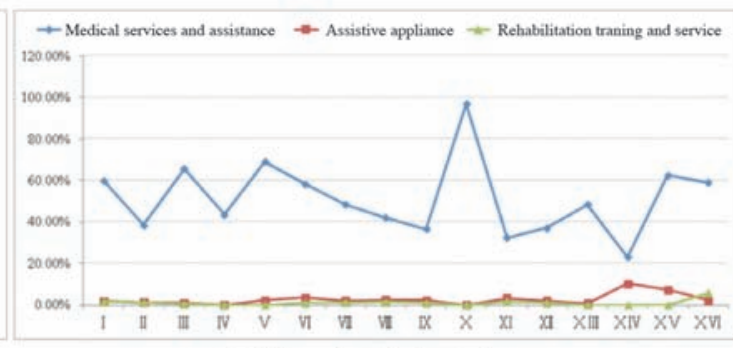

(b) Status of medical assistance

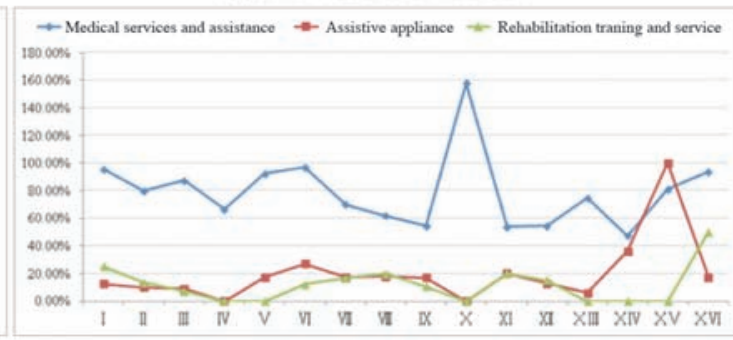

(d) Requirement satisfaction about medical assistance

Fig. 6. Social support of unintentionally injured disabled people aged 15-60 years across various city types. 
the world's population has a disability (Mont, 2007), and they are among the poorest of the poor (DFID, 2000). Social support can help poor disabled people shake off poverty. In P.R. China, social support activities usually involve such forms as assisting the poor disabled person to raise funds, implement preferential policies, select projects and study technology (Office of the Second Chinese National Sample Survey on Disability, 2007). In the survey, social support was substantially underweight in city types IV, $\mathrm{X}$ and XIV. However, cities of types IV and XIV had relatively sound social security systems that may provide ideas for the local governments for adapting intervention policies.

\section{Discussion}

Since more than $40 \%$ of all disabilities in the population as a whole were found in the young and middleaged (Office of the Second Chinese National Sample Survey on Disability, 2007), this part of the population is an important target for disability prevention, control and service measures. The additional fact that out of these various forms of disability the prevalence rate of unintentional injury reached almost $20 \%$ is a cause of great concern. The demonstration by this study that this type of disability varies significantly across cities with different social security systems and industrial structures is an additional piece of information that is critical when planning preventive actions. Since the most common causes were due to traffic accidents and working accidents, preventive measures should focus on high-risk groups and adapt to the most common injuries.

The reasons for higher unintentional injury-related disabilities occurring in border trade cities are not known, but may be associated with factors such as a large migrant population, heavy traffic coupled with low supervision, increased presence of vulnerable road users and higher rates of driving while under the influence of alcohol (Wang et al., 2008). The fact that more than half the number of disabilities occurred in the minority population emphasises the need for improving their lot with a focus on education.

In addition to analysis the spatial heterogeneity of the prevalence of disability caused by unintentional injury, the nature of the disability within the target group as it is a major obstacle for community integration. The unfair discrimination of disabled people with regard to employment requires support mechanisms and implementation of and reformed policy formulation taking into account that disability does not intrinsically render a person vulnerable, but it is rather the lack of access, information and support that intensifies vulnerability (Lang et al., 2011). As discussed by Mannan et al. (2012) every effort should be made to give all individuals equal opportunities with regard to accessing services such as employment opportunity, vocational training and job promotion. A required satisfaction index regarding vocational education opportunities for disabled people may be needed to ensure that each city government's efforts to eliminate this discrimination are attended to. However, the needs vary considerably between the city types as shown here. Local governments, particularly of the cities belonging to types IV, X and XI should therefore make greater effort to increase participation of people with disabilities and provide vocational training opportunities.

Promoting health, quality of life, and participation of persons with disabilities is a relatively recent development in public health (Krahn and Campbell, 2011). Fig. 5b shows that that there are alternative ways of providing disability rehabilitation services or assistance. In all city types, most disabled people depended on hospitals or special medical institutions for medical aid helping them to adapt to society and become selfreliant. Reform and promotion are needed with respect to support appliances and/or rehabilitation training since few disabled people use assistance in the form of support appliances and/or rehabilitation training provided (Office of the Second Chinese National Sample Survey on Disability, 2007).

Some limitations of this study should be mentioned. Although we used the place of residence for the spatial analysis, it may not be the same as the city where the incident occurred (even if this is unlikely). The temporal aspect of exposure to risk experienced by people was not taken into consideration in this analysis. Also, the study did not cover all disabilities caused by unintentional injuries because of data limitations. In addition, since this was a cross-sectional study, it is difficult to determine causal relationships between social security systems and industrial structure factors and disabilities caused by unintentional injuries amongst the target population.

\section{Conclusions}

Disabilities caused by unintentional injury constitute a major public health problem in P.R. China. This paper aims to introduce classification to direct help and support to the cities most in need. To the best of our knowledge, this is the first study to analyse disabilities caused by injury and their spatial distribution to support a working strategy for injury prevention. The study results illustrate that the prevalence of disability caused by injury is clustered with respect to 
space and age. The findings encourage focusing resource allocation at identified priority areas (i.e. high-risk cities) in order to reduce the burden experienced. Spatial analysis was further demonstrated to be a useful approach in mapping the distribution of disabilities caused by unintentional injury. Although our study refers only to disabilities caused by unintentional injuries, we believe that the study framework can be generalised to include also other disabilities.

\section{Acknowledgements}

This work was supported by the National Natural Science Foundation of China (no. 41101431), the State Key Funds of Social Science Project (Research on Disability Prevention Measurement in China, no. 09\&ZD072), and the Yong Talent Fund of Institute of Geographic Sciences and Natural Resources Research, CAS (no. 2012RC201).

\section{References}

Chandran A, Hyder AA, Peek-Asa C, 2010. The global burden of unintentional injuries and an agenda for progress. Epidemiol Rev 32, 110-120.

Dai JF, Wang SY, Wang C, Zhao GX, Dong XM, 2010. Epidemiological study on disability caused by injury in the Chinese population. Chin J Epidemiol 31, 1107-1110.

DFID, 2000, Disability, poverty and development. Available at: http://www.dfid.gov.uk/pubs/files/disability.pdf (accessed on October 2012).

Gwen EJ, 1997. Advancement opportunity issues for persons with disabilities. Hum Resour Manage R 7, 55-76.

Krahn G, Campbell VA, 2011. Evolving views of disability and public health: the roles of advocacy and public health. Disabil Health J 4, 12-18.

Kruskal WH, Wallis WA, 1952. Use of ranks in one-criterion variance analysis. J Am Statist Assoc 47, 583-621.

Lam LT, Yang L, 2007. Short duration of sleep and unintentional injuries among adolescents in China. Am J Epidemiol 166, 1053-1058.

Lancet, 2011. Championing good health for people with disabilities. Lancet 378, 1895.

Lang R, Kett M, Groce N, Trani JF, 2011. Implementing the United Nations Convention on the rights of persons with disabilities: principles, implications, practice and limitations. ALTER-European Journal of Disability Research 5, 206-220.

Lewit EM, Baker LS, 1995. Unintentional injuries. Future Child 5, 214-222.

Lin JY, 2010. New structural economics: a framework for rethinking development. Policy Research Working Paper 5197. Washinton DC: The World Bank.
Mannan H, MacLachlan M, McVeigh J, The EquitAble Consortium, 2012. Core concepts of human rights and inclusion of vulnerable groups in the United Nations Convention on the rights of persons with disabilities. ALTER-European Journal of Disability Research 6, 159-177.

Mont D, 2007. Measuring disability prevalence, social protection discussion paper no. 0706. The World Bank.

Mont D, Loeb M, 2010. A functional approach to assessing the impact of health interventions on people with disabilities. ALTER-European Journal of Disability Research 4, 159-173.

Nelson HJ, 1955. A service classification of American cities. Econ Geogr 31, 189-210.

Office of the Second China National Sample Survey on Disability, 2007. Documentation of the Second China National Sample Survey on Disability. Beijing: China Statistics Press.

Peng X, Song S, Sullivan S, Qiu J, Wang W, 2010. Ageing, the urban-rural gap and disability trends: 19 years of experience in China 1987 to 2006. PLoS One 5, e12129.

Postel MW, Jaung MS, Chen G, Yu S, Stallones L, Xiang H, 2008. Farm work-related injury among middle school students in rural China. J Agric Saf Health 15, 129-142.

Sun YH, Yu IT, Zhang Y, Fan YP, Guo SQ, Wong TW, 2006 a. Unintentional injuries among primary and middle school students in Maanshan City, eastern China. Acta Paediatr 95, 268275.

Wang JF, Liu XH, Peng L, Chen HY, Driskell L, Zheng XY, 2012. Cities evolution tree and applications to predicting urban growth. Popul Environ 33, 186-201.

Wang SY, Li YH, Chi GB, Xiao SY, Smith JO, Stevenson M, Philips MR, 2008. Injury-related fatalities in China: an underrecognised public-health problem. Lancet 372, 1765-1773.

Ward Jr JH, 1963. Hierarchical grouping to optimize an objective function, J Am Stat Assoc, 58, 236-244.

WHO, 2005. World Health Assembly Resolution WHA58.23 on disability, including prevention, management and rehabilitation. Geneva: World Health Organization.

WHO, 2007. Injury-related disability and rehabilitation. Geneva: World Health Organization.

WHO, 2008. The global burden of disease: 2004 update. Geneva: World Health Organization.

WHO, 2011. World report on disability. Geneva: World Health Organization.

Xiang HY, Wang ZZ, Stallones L, Keefe T, Huang XZ, Fu XH, 2000. Agricultural work-related injuries among farmers in Hubei, People's Republic of China. Am J Public Health 90, 1269-1276.

Zheng XY, Chen G, Song XM, Liu JF, Yan LJ, Du W, Pang LH, Zhang L, Wu JL, Zhang BZ et al., 2011. Twenty-year trends in the prevalence of disability in China. Bull World Health Organ 89, 788-797. 